\title{
Interaction of Temperature and Moisture on Infection of Wild Rice by Bipolaris oryzae in the Growth Chamber
}

\author{
J. A. Percich, Professor, R. F. Nyvall, Professor, D. K. Malvick, Research Fellow, Department of Plant Pathology, \\ University of Minnesota, St. Paul 55105; and C. L. Kohls, Plant Pathologist, American Cyanamid Company, P.O. \\ Box 700, Princeton, NJ 08540
}

\begin{abstract}
Percich, J. A., Nyvall, R. F., Malvick, D. K., and Kohls, C. L. 1997. Interaction of temperature and moisture on infection of wild rice by Bipolaris oryzae in the growth chamber. Plant Dis. 81:1193-1195.

Infection of wild rice (Zizania palustris) flag leaves by Bipolaris oryzae was studied at temperatures of 5 to $35^{\circ} \mathrm{C}$ and wet periods of 2 to $36 \mathrm{~h}$ after inoculation. Lesion densities (lesions $/ \mathrm{cm}^{2}$ ) increased with increasing wet periods depending on optimum temperature. High rates of infection occurred at 25 and $30^{\circ} \mathrm{C}$ and generally increased with continuous wet periods of $16,18,24$, and $28 \mathrm{~h}$. There were no lesions at $5^{\circ} \mathrm{C}$ and few at 10 and $35^{\circ} \mathrm{C}$. Lesion densities declined when wet periods of 2,4 , or $6 \mathrm{~h}$ were interrupted by dry periods of $4,6,8,10$, or $12 \mathrm{~h}$ followed by a final $14 \mathrm{~h}$ of wetness. Lesion densities decreased at all temperatures with increased dry periods regardless of the initial wet period. The interaction of dry period length $\times$ wet period length $\times$ temperature was significant at the $0.5 \%$ level. With continuous wet periods, lesion numbers were highest at 25 to $30^{\circ} \mathrm{C}$.
\end{abstract}

Fungal brown spot of wild rice, caused by Bipolaris oryzae (Breda de Haan) Shoemaker, is a severe disease that occurs on leaves, stems, and flowers of cultivated wild rice (Zizania palustris L.) in Minnesota (7). Under favorable environmental conditions for disease, fungal brown spot can cause up to $67 \%$ yield loss $(9,10)$. Based on symptomatology and etiology, the disease commonly referred to as fungal brown spot has been separated into two diseases; fungal brown spot, caused by $B$. oryzae, and spot blotch caused by $B$. sorokiniana (Sacc.) Shoemaker (14). Previously reported yield losses to this disease likely resulted from both fungal brown spot and spot blotch.

The effects of moisture and temperature on infection by $B$. oryzae have been investigated under both controlled and field conditions for brown spot disease of rice (Oryzae sativa). Results from these studies, however, are often contradictory $(1,2,5,6,8)$. This may be partially due to physiological differences between isolates from the Philippines and the southern United States (15).

Corresponding author: J. A. Percich

E-mail: jamesp@puccini.crl.umn.edu

Published as paper No. 20154 of the contribution series of the Minnesota Agricultural Experiment Station based on research conducted under Project 22-68

Accepted for publication 26 June 1997.

Publication no. D-1997-0730-02R

(C) 1997 The American Phytopathological Society
Germination of B. oryzae conidia differ between isolates from rice and wild rice. Generally, conidia from isolates obtained from rice germinate on a selective medium at 16 to $40^{\circ} \mathrm{C}$, with optimal germination and growth occurring at $28^{\circ} \mathrm{C}(15)$. Infection of rice occurs at temperatures of 20 to $30^{\circ} \mathrm{C}$, with optimal infection at 20 to $25^{\circ} \mathrm{C}$ with 4 or more h at $100 \%$ relative humidity (RH; 6,17). Conidia from isolates obtained from wild rice, however, germinate at 5 to $45^{\circ} \mathrm{C}$ on water agar, with optimal infection at 28 to $30^{\circ} \mathrm{C}$ with 8 or more h of 96 to $100 \% \mathrm{RH}$. The survival, primary inoculum dispersal, early infection, and subsequent spread of $B$. oryzae in commercial wild rice fields in Minnesota have been studied (3).

Currently, the fungicide propiconazole (Tilt) is used to control fungal brown spot on cultivated wild rice in Minnesota. The fungicide is normally applied to wild rice on a calendar schedule beginning in early July or when environmental conditions are thought to be favorable for disease to occur $(9,10,16)$. Therefore, it is necessary to understand the precise environmental conditions necessary for infection and disease development in order to more effectively time the application of the fungicide and perhaps implement alternative disease control measures $(7,12)$.

There have been no studies on the effects of environment on infection of cultivated wild rice by $B$. oryzae under controlled conditions. Therefore, the objective of this study was to determine the effects of temperature and continuous or intermittent moisture on infection of wild rice by B. oryzae in the growth chamber.

\section{MATERIALS AND METHODS}

Dew chambers were constructed of polyvinyl chloride (PVC) pipe covered with clear polyethylene plastic $(0.01 \mathrm{~mm})$ by the method of Krupinsky and Scharen (11). These chambers were assembled inside environmental growth chambers $(1.2$ by 2.3 by $1.7 \mathrm{~m}$; Integrated Development \& MFG., Environmental Growth Chambers). Pipe (PVC, $5 \mathrm{~cm}$ diameter) had 1.3mm-diameter holes placed at $10-\mathrm{cm}$ intervals to evenly distribute mist above the plants.

Wild rice seed (cultivar K-2) was stored for 4 months at $2^{\circ} \mathrm{C}$, then germinated in tap water at $24^{\circ} \mathrm{C}$. Seedlings were placed individually in plastic pots $(15 \mathrm{~cm}$ diameter $)$ previously filled within $2 \mathrm{~cm}$ of the top with a soil mix (sandy loam/sand/peat: composted manure, 7:3:2:1), $\mathrm{pH}$ 6.9, amended with $3.5 \mathrm{~g}$ of a 10-10-10 fertilizer. The remaining $2 \mathrm{~cm}$ of each pot was filled with washed silica sand to control growth of algae. Pots then were placed in wooden frames $(91$ by $71 \mathrm{~cm}$ ) lined with 4 layers of $0.01 \mathrm{~mm}$ black polypropylene plastic. The frames were filled with tap water to a depth of $13 \mathrm{~cm}$, and maintained throughout the experiment. Supplemental lighting was a mixture of $60 \mathrm{~W}$ incandescent, $160 \mathrm{~W}$ cool white, and Gro-lux fluorescent bulbs (ratio 5:5:3; Sylvania Lighting Products Group, Danvers, MA) for $16.5 \mathrm{~h}$ at $300 \mu \mathrm{mol} \cdot \mathrm{m}^{-2} \cdot \mathrm{s}^{-1}$, measured at mid-foliage with a Quantum Radiometer Photometer (Model L1-185, LI-COR Inc. Lincoln, NE). An additional granular $2.5 \mathrm{~g}$ of urea (46-0-0) fertilizer was placed into the water of each flat during the early boot stage of plant development.

$B$. oryzae isolate (B08055) was isolated originally from a wild rice plant in a commercial Minnesota field and was inoculated to wild rice every 6 months to maintain pathogenicity. BO8055 did not differ significantly in percent conidial germination or germ tube numbers when compared to nine other $B$. oryzae isolates on either water or potato dextrose agar (PDA; 13). Also, germ tube length, appressorium development, and infection efficiency on wild rice (cultivar K-2) did not differ from other B. oryzae isolates (13). BO8055 was cultured on PDA (Difco Laboratories, Detroit) in petri dishes for 4 weeks at $24^{\circ} \mathrm{C}$ in the dark to produce conidia. Conidia were removed from cultures by suspension in Soltrol 120 oil (Phillips Chemical Co., 
Pasadena, TX), and the concentration was adjusted to approximately $1.0 \times 10^{3}$ conidia/ml.

The middle portion (8 to $10 \mathrm{~cm}$ in length) of the uppermost fully expanded leaf from each plant in the boot stage of development was delineated as the inoculation area with a permanent felt tip marker. Each inoculation area was uniformly inoculated using a DeVilbiss atomizer with a conidial suspension until lightly wet as described by Browder (4).

Continuous and intermittent wet period treatments were conducted at 5, 10, 15, 20, 25,30 , or $35^{\circ} \mathrm{C}$. Prior to placement in the dew chambers, plants were misted with a mixture of $0.026 \%$ Tween 40 (Polyoxyethylene titan monopalmitate, Sigma Chemical Co., St. Louis) in deionized water. In the continuous wet period, plants were wet for $2,4,6,8,10,12,14,16,18$, $20,24,28$, or $36 \mathrm{~h}$ after inoculation. In the intermittent wet period, plants were initially kept wet for 2,4 , or $6 \mathrm{~h}$, followed by dry periods $(85 \% \mathrm{RH})$ when plants were removed from the dew chamber for $4,6,8$,
10,12 , or $14 \mathrm{~h}$. After the dry periods, plants were placed back in the dew chamber for a final $14 \mathrm{~h}$ wet period. After each wet period, plants were returned to the greenhouse for lesion development. Each treatment consisted of 11 plants and was replicated three times. The entire experiment was repeated twice.

Seven days after initiation of the wet periods, inoculated areas were excised from the plants, placed in head bags, pressed, and dried at $24^{\circ} \mathrm{C}$ to later determine lesions $/ \mathrm{cm}^{2}$. Pressed samples were rehydrated for $30 \mathrm{~min}$ in $250 \mathrm{ml}$ water mixed with $0.3 \mathrm{ml}$ Tween 40 and examined with a Quebec colony counter (American Optical). Leaf area was determined with a portable area meter and transparent belt conveyer accessory (models L1-3000 and L13050A, LI-COR).

Data were analyzed with analysis of variance (ANOVA) using the IVAN interactive statistical computer program (18). Coefficients of determination $\left(R^{2}\right)$ were calculated using simple nonlinear regression, based on a secondary polynomial equation (Excel, Microsoft Corp., Redmond, WA).

\section{RESULTS AND DISCUSSION}

A highly significant $(P<0.005)$ interaction existed between the continuous wet periods and temperature. These two factors greatly influenced lesion density on the flag leaf (Table 1). Disease symptoms occurred at temperatures of 10 to $35^{\circ} \mathrm{C}$ and continuous wetness periods of 10 to $36 \mathrm{~h}$, with maximum numbers of lesions $/ \mathrm{cm}^{2}$ occurring at $25^{\circ} \mathrm{C}$ and 20 to $24 \mathrm{~h}$ of wetness (Table 1). No disease symptoms occurred at $5^{\circ} \mathrm{C}$ (data not shown) and few at 10 or $35^{\circ} \mathrm{C}$. Continuous moisture of 2 to 8 $\mathrm{h}$ (data not shown), regardless of temperature, did not result in disease expression. In general, lesion density increased as continuous wet periods increased from 10 to $24 \mathrm{~h}$, and decreased at continuous wet periods of 28 to $36 \mathrm{~h}$. The $R^{2}$ values (Table 1 ) reveal relationships between incubation temperature, continuous wet periods, and lesion numbers. $R^{2}$ values for continuous wet periods versus lesion numbers were

Table 1. Mean number of lesions $/ \mathrm{cm}^{2}$ on the flag leaf of Zizania palustris infected with Bipolaris oryzae at various temperatures and periods of continuous wetness

\begin{tabular}{|c|c|c|c|c|c|c|c|}
\hline \multirow[b]{2}{*}{ Continuous wet periods (h) } & \multicolumn{7}{|c|}{ Incubation temperature $\left({ }^{\circ} \mathrm{C}\right)$} \\
\hline & 10 & 15 & 20 & 25 & 30 & 35 & $R^{2 \mathbf{a}}$ \\
\hline 10 & 0.0 & 0.0 & $0.5^{\mathrm{b}}$ & 1.0 & 2.0 & 0.1 & 0.44 \\
\hline 12 & 0.0 & 0.0 & 2.1 & 8.0 & 4.5 & 0.1 & 0.55 \\
\hline 14 & 0.2 & 2.0 & 3.6 & 9.6 & 6.8 & 0.6 & 0.68 \\
\hline 16 & 0.2 & 2.4 & 4.3 & 12.6 & 9.4 & 0.4 & 0.64 \\
\hline 18 & 0.3 & 2.5 & 4.8 & 16.2 & 11.4 & 0.2 & 0.60 \\
\hline 20 & 0.5 & 2.6 & 3.8 & 22.6 & 15.8 & 0.3 & 0.50 \\
\hline 24 & 1.2 & 2.5 & 3.0 & 22.7 & 18.6 & 0.4 & 0.45 \\
\hline 28 & 0.4 & 3.2 & 3.1 & 20.0 & 14.0 & 0.1 & 0.50 \\
\hline 36 & 0.3 & 2.5 & 3.5 & 14.6 & 11.0 & 0.2 & 0.56 \\
\hline$R^{2 \mathrm{c}}$ & 0.58 & 0.84 & 0.44 & 0.95 & 0.92 & 0.14 & \\
\hline
\end{tabular}

${ }^{a}$ Coefficient of determination $\left(R^{2}\right)$ for incubation temperature vs. lesion number.

${ }^{\mathrm{b}}$ Mean value of 11 plants in each of three replications.

${ }^{\mathrm{c}}$ Coefficient of determination $\left(R^{2}\right)$ for continuous wet period vs. lesion number.

Table 2. Mean number of lesions $/ \mathrm{cm}^{2}$ on the flag leaves of Zizania palustris infected with Bipolaris oryzae at various temperatures and intermittent wet and dry periods. The dry periods were followed by $14 \mathrm{~h}$ of continuous wetness

\begin{tabular}{|c|c|c|c|c|c|c|c|}
\hline \multirow[b]{2}{*}{ Wet $h$} & \multirow[b]{2}{*}{ Dry h } & & \multicolumn{5}{|c|}{ Incubation temperature $\left({ }^{\circ} \mathrm{C}\right)$} \\
\hline & & & 15 & 20 & 25 & 30 & 35 \\
\hline \multirow{6}{*}{2} & 4 & & $0.8^{\mathrm{a}}$ & 0.5 & 11.5 & 7.3 & 0.1 \\
\hline & 6 & & 5.1 & 0.7 & 4.2 & 5.7 & 2.6 \\
\hline & 8 & & 1.4 & 0.2 & 11.2 & 1.9 & 0.8 \\
\hline & 10 & & 1.6 & 1.1 & 3.2 & 0.6 & 0.5 \\
\hline & 12 & & 0.2 & 0.4 & 1.3 & 0.1 & 0.5 \\
\hline & & $R^{2 \mathrm{~b}}$ & -0.42 & 0 & -0.52 & -0.96 & -0.27 \\
\hline \multirow[t]{6}{*}{4} & 4 & & 0.3 & 0.1 & 10.0 & 5.5 & 2.2 \\
\hline & 6 & & 1.0 & 1.7 & 8.8 & 0.2 & 1.9 \\
\hline & 8 & & 0.2 & 1.1 & 4.5 & 1.1 & 0.7 \\
\hline & 10 & & 0.3 & 0.6 & 1.0 & 0.0 & 0.0 \\
\hline & 12 & & 0.4 & 0.1 & 0.3 & 0.0 & 0.0 \\
\hline & & $R^{2 \mathrm{~b}}$ & 0 & -0.70 & -0.95 & -0.80 & -0.94 \\
\hline \multirow[t]{6}{*}{6} & 4 & & 1.0 & 0.4 & 7.8 & 1.3 & 0.2 \\
\hline & 6 & & 1.0 & 0.4 & 9.4 & 2.7 & 0.4 \\
\hline & 8 & & 0.5 & 0.3 & 7.2 & 2.0 & 0.1 \\
\hline & 10 & & 1.5 & 1.3 & 3.4 & 0.7 & 0.0 \\
\hline & 12 & & 0.0 & 0.6 & 0.2 & 1.2 & 0.1 \\
\hline & & $R^{2 \mathrm{~b}}$ & -0.30 & -0.39 & -0.97 & -0.37 & -0.38 \\
\hline
\end{tabular}

${ }^{a}$ Mean of 11 flag leaves in each of three replications.

${ }^{\mathrm{b}}$ Coefficient of determination $\left(R^{2}\right)$ for incubation dry $\mathrm{h}$ vs. lesion numbers at various incubation temperatures. 
inconsistent across various incubation periods; however, the $R^{2}(0.95)$ was the highest at $25^{\circ} \mathrm{C}$ (Table 1 ).

Significant disease development by $B$. oryzae, indicated by lesion numbers in the continuous wet period treatments, occurred in a narrower temperature range than spore germination. In previous studies $B$. oryzae germinated 80 to $90 \%$ in vitro after $2 \mathrm{~h}$ at 15 to $35^{\circ} \mathrm{C}$, but longer wet periods are needed for infection to be successful (13). The majority $(95 \%)$ of $B$. oryzae conidia produced two bipolar germ tubes on wild rice at 5 or $10^{\circ} \mathrm{C}$. However, germination was very slow with little infection at these temperatures even after continuous wet periods of $24 \mathrm{~h}$ or more (13). The importance of intercalary cell germination to infection during intermittent wet periods has not been investigated. An extended dry period following a wet one may damage bipolar germ tubes, but would probably have little or no effect on the ability of the intercalary cells at a later time to produce germ tubes during favorable environmental conditions. Also, B. oryzae isolates differ in the speed at which conidial germination and subsequent infection takes place (13). Consequently, these two factors may be important, because the paddy environment in Minnesota during July and August is often characterized by long periods of wet nights with intermittent dry days $(7,9)$.

Temperature in the intermittent wet period study (Table 2) significantly $(P<$ 0.005 ) influenced lesion density. Lengths of the initial wet and dry periods at a given temperature were negatively related to lesion density in a linear manner. The linear relationship $\left(R^{2}\right)$ was strongest at 25 to $30^{\circ} \mathrm{C}\left(R^{2}=0.95-0.97\right)$. Lesion density generally increased with decreasing dry periods and increasing temperature of 15 to $25^{\circ} \mathrm{C}$ (Table 2). Lesion density declined at 30 and $35^{\circ} \mathrm{C}$. No lesions developed at 5 or $10^{\circ} \mathrm{C}$ (data not shown), regardless of the length of wet and dry periods. Increasing the length of the wet periods beyond $4 \mathrm{~h}$ and the dry period beyond $12 \mathrm{~h}$ caused a decrease in the number of lesions per $\mathrm{cm}^{2}$ at incubation temperatures of 15 to $35^{\circ} \mathrm{C}$.

The wet period $\times$ temperature interaction was not significant $(P<0.5)$. This indicates the incubation temperature during the short initial wet period did not significantly influence the effect of wet period on lesion density. The interaction of dry period length and incubation temperature, how- ever, was significant $(P<0.005)$.

Lesion density from the intermittent wet period study was lower than equivalent continuous wet period lengths. The fungus had fewer successful infections with increasing lengths of dryness after initial wet periods. Lesion formation by $B$. oryzae on wild rice cultivar K-2 occurred by $36 \mathrm{~h}$ after inoculation. Hyphae emerged through the cuticle and stomata by $48 \mathrm{~h}$ (96 to $100 \% \mathrm{RH}, 28$ to $30^{\circ} \mathrm{C}$ ) and conidiophore initials and mats of hyphae on the cuticle surface occurred at 48 to 72 h (96 to $100 \%$ $\mathrm{RH})$ (13). Isolates of $B$. oryzae from rice, $O$. sativa, produced germ tubes 10 to $14 \mathrm{~h}$ after inoculation at $100 \% \mathrm{RH}$ (17). Because varying periods of high relative humidity occur frequently in wild rice stands, it is likely the conidial germination of $B$. oryzae during July and August in Minnesota may occur after only 6 to 8 h (9). Dew periods in Minnesota may occur nightly, and are often 12 or more $h$ in duration in the middle of the plant canopy (10). Cultivated wild rice tillers profusely, and at maturity may be greater than $2 \mathrm{~m}$ in height with leaves $1 \mathrm{~m}$ long. This growth produces an understory of densely packed leaves and stems that is characterized by long dew periods and poor penetration by wind or aerially applied fungicides. The upper canopy is less dense and has shorter dew periods, good air circulation, and excellent fungicide penetration (9). Because of differences in wet periods and fungicide deposition, the flag leaf may have only a few small lesions, while older leaves in the understory may have a very high disease severity rating $(9,10,16)$. The future use of dwarf wild rice cultivars and the more precise control of plant density will reduce canopy development and long periods of leaf wetness. Thus, these factors should result in reduced infection and better fungicide coverage resulting in improved FBS management.

\section{ACKNOWLEDGMENTS}

We thank Cathy Huot for technical assistance.

\section{LITERATURE CITED}

1. Abeygunawardena, D. V. M. 1967. Conditions that favor Helminthosporium leaf disease and its control in Ceylon. Tokyo Agric. Forest Fish Res. Council Trop. Agric. Res. Serv. 1:171-179.

2. Ashour, W. A., Sirry, A. R., Abdel-Huk, T. M., and Kamel, S. M. 1973. Effect of different environmental factors on blast and brown spot diseases of rice in Arab Republic of Egypt.
Agric. Res. Rev. 51:29-44.

3. Brantner, J. R. 1995. Survival, inoculum sources and propiconazole sensitivity of $\mathrm{Bi}$ polaris species causing fungal brown spot of wild rice and host sensitivity to ophiobolin. M. Sci. Thesis, University of Minnesota, St. Paul.

4. Browder, L. E. 1971. Pathogenic specialization in cereal rust fungi, especially Puccinia recondita $\mathrm{f}$. sp. tritici: concepts, methods of study and application. U.S. Dep. Agric. Tech. Bull. 1432.

5. Hemmi, T., and Nojima, T. 1931. On the relation of temperature and period of continuous wetting to the infection of the rice plant by Ophiobolus miyabeanus. Forshm. Geb. Pflkrankh. 1:84-89.

6. Imura, J. 1940. On the influence of sunlight upon the incubation period of the Helminthosporium disease of the rice plant. Ann. Phytopathol. Soc. Jpn. 10:16-26.

7. Johnson, D. R., and Percich, J. A. 1992. Wild rice domestication, fungal brown spot disease, and the future of commercial production in Minnesota. Plant Dis. 76:1193-1198.

8. Katsura, K. 1937. On the relation of atmospheric humidity to the infection of the rice plant by Ophiobolus miyabeanus Ito and Kuribayashi and to the germination of its conidia. Ann. Phytopathol. Soc. Jpn. 7:105124.

9. Kohls, C. L. 1985. Epidemiology, yield reductions and field surveys of fungal brown spot of cultivated wild rice. Ph.D. thesis, University of Minnesota, St. Paul.

10. Kohls, C. L., and Percich, J. A. 1987. Wild rice losses associated with growth-stage-specific fungal brown spot epidemics. Plant Dis. 71:419-422.

11. Krupinsky, J. M., and Scharen, A. L. 1983. A high humidity incubation chamber for foliar pathogens. Plant Dis. 67:84-86.

12. Malvick, D. K., and Percich, J. A. 1993. Hydroponic culture of wild rice (Zizania palustris L.) and its application to studies of silicon nutrition and fungal brown spot disease. Can. J. Plant Sci. 738:969-975.

13. Mitchell-Schickli, L. M. 1984. Early infection events of Bipolaris oryzae on wild rice. M Sci. thesis, University of Minnesota, St. Paul.

14. Nyvall, R. F., Percich, J. A., and Brantner, J. R. 1994. Fungal brown spot of cultivated wild rice is two different diseases. Phytopathology 84:1102.

15. Ocfemia, G. O. 1924. The Helminthosporium disease of rice occurring in the Southern United States and in the Philippines. Am. J. Botany 11:385-408.

16. Percich, J. A. 1989. Comparison of propiconazole rates for control of fungal brown spot of wild rice. Plant Dis. 73:588-589.

17. Sherf, A. F., Page, R. M., Tullis, E. C., and Morgan, T. L. 1947. Studies on factors affecting the infectivity of Helminthosporium oryzae. Phytopathology. 37:281-290.

18. Weisberg, S., and Koehler, K. J. 1981. IVAN, users manual, version 2.1. Tech. Rep. 266, School of Statistics, University of Minnesota, St. Paul. 